\begin{tabular}{|c|c|c|c|}
\hline \multirow{3}{*}{$\begin{array}{r}\text { Case Reports in } \\
\text { Gastroenterology }\end{array}$} & Case Rep Gastroenterol 2 & & \multirow[b]{2}{*}{ Oparger } \\
\hline & $\begin{array}{l}\text { DOI: } 10.1159 / 000446018 \\
\text { Publisned onmine. TViay zo, } 2016\end{array}$ & $\begin{array}{l}\text { (c) } 2016 \text { The Author(s) } \\
\text { Published by S. Karger AG, Basel } \\
\text { www.karger.com/crg }\end{array}$ & \\
\hline & $\begin{array}{l}\text { This article is licensed under } \\
\text { International License (CC BY- } \\
\text { Usage and distribution for comn }\end{array}$ & $\begin{array}{l}\text { nons Attribution-NonCommercial } 4 . \\
\text { ger.com/Services/OpenAccessLicense) } \\
\text { uires written permission. }\end{array}$ & \\
\hline
\end{tabular}

\title{
The Challenging Buried Bumper Syndrome after Percutaneous Endoscopic Gastrostomy
}

\author{
Ibrahim Afifi $^{a} \quad$ Ahmad Zarour $^{\mathrm{a}} \quad$ Ammar Al-Hassani $^{\mathrm{a}} \quad$ Ruben Peralta $^{\mathrm{a}}$ \\ Ayman El-Menyar ${ }^{b, c}$ Hassan Al-Thania \\ ${ }^{a}$ Trauma Surgery Section, Department of Surgery, Hamad General Hospital (HGH), \\ Doha, Qatar; ${ }^{b}$ Clinical Research, Trauma Surgery, Hamad General Hospital (HGH), \\ Doha, Qatar; ${ }^{C}$ Clinical Medicine, Weill Cornell Medical College, Doha, Qatar
}

\section{Keywords}

Buried bumper syndrome - Percutaneous endoscopic gastrostomy tube · Complication .

Treatment · Trauma

\section{Abstract}

Buried bumper syndrome (BBS) is a rare complication developed after percutaneous endoscopic gastrostomy (PEG). We report a case of a 38-year-old male patient who sustained severe traumatic brain injury that was complicated with early BBS after PEG tube insertion. On admission, bedside PEG was performed, and 7 days later the patient developed signs of sepsis with rapid progression to septic shock and acute kidney injury. Abdominal CT scan revealed no collection or leakage of the contrast, but showed malpositioning of the tube bumper at the edge of the stomach and not inside of it. Diagnostic endoscopy revealed that the bumper was hidden in the posterolateral part of the stomach wall forming a tract inside of it, which confirmed the diagnosis of BBS. The patient underwent laparotomy with a repair of the stomach wall perforation, and the early postoperative course was uneventful. Acute BBS is a rare complication of PEG tube insertion which could be manifested with severe complications such as pressure necrosis, peritonitis and septic shock. Early identification is the mainstay to prevent such complications. Treatment selection is primarily guided by the presenting complications, ranging from simple endoscopic replacement to surgical laparotomy. 


\section{Case Reports in Gastroenterology}

Case Rep Gastroenterol 2016;10:224-232

(c) 2016 The Author(s). Published by S. Karger AG, Basel www.karger.com/crg

Afifi et al:: The Challenging Buried Bumper Syndrome after Percutaneous Endoscopic Gastrostomy

\section{Introduction}

Gastrostomy is a frequently used enteral access technique for feeding which could be achieved and guided with endoscopy, radiological imaging, or surgical techniques (open or laparoscopic) [1]. Currently, percutaneous endoscopic gastrostomy (PEG) placement is widely accepted for medium- and long-term enteral feeding of patients with neurologic deficits, dysphagia, oral or esophageal cancer, major trauma, burns, and short-bowel syndrome [2]. However, early and late complications of PEG tube placement are infrequently reported in some patients $(1.5-1.9 \%)$ [3]. Buried bumper syndrome (BBS) is a rare complication which occurs when the inner bumper migrates through the gastric wall and is lodged between gastric wall and skin [4]. It is a late complication that usually develops 3-6 months after placement of a PEG tube, but few reports showed its early occurrence within 5-30 days of tube placement [5]. It is usually manifested with abdominal pain, tube malfunction and leakage around the tube [6]. It has been proposed that excessive pressure between the internal and external bolsters of the gastrostomy tube can cause mucosal ischemia, necrosis and infection resulting in BBS $[7,8]$. BBS could be suspected in patients based on history, physical examination and failure to insert and rotate the PEG tube before repositioning the external bumper [9]. The most definitive technique to diagnose BBS is gastrointestinal endoscopy, whereas imaging techniques such as ultrasonography and abdominal computerized tomography (CT) are also useful for diagnosis [6]. The management options for BBS range from a conservative approach to surgery or endoscopic repair [8]. Moreover, an appropriate patient selection and management approach are the important determinants for successful outcomes. We report the case of a patient with severe traumatic brain injury who developed early BBS after PEG tube insertion, which was successfully managed by open laparotomy.

\section{Case Presentation}

A 38-year-old male driver presented to the emergency room with severe traumatic brain injury after a motor vehicle crash. On admission, the patient had a poor neurologic status with a GCS of 7. He underwent standard TICU protocol to manage the underlying injuries. He was found to have right parietal subdural hematoma, bilateral tempo parietal contusions, mild brain edema, odontoid base fracture extending along the lateral masses of the second cervical vertebra and fracture of the left clavicle. Initially, the patient developed paroxysmal autonomic instability with dystonia (PAID) syndrome as an early complication of severe brain injury which was controlled with medications such as benzodiazepine, propranolol and baclofen.

Percutaneous dilation tracheostomy and PEG were performed at the bedside. Percutaneous dilation tracheostomy was successfully performed with the aid of bronchoscopy, and post-procedure radiography was performed to assure the position. PEG was performed with a tube level of $4 \mathrm{~cm}$ at the abdominal wall and bumper position inside the stomach (fig. 1), and the patient was kept fasting orally for $24 \mathrm{~h}$. Feeding was started later with no observed residual volume and feeding intolerance. At the 7th day after PEG tube insertion, the patient developed signs of sepsis which rapidly progressed to septic shock (temperature $39.5^{\circ} \mathrm{C}$, blood pressure $85 / 50$, heart rate 100 and respiratory rate $26 / \mathrm{min}$ ), INR increased to 1.6 , while WBC dropped from 7,000 to 4,000 and the patient developed acute kidney injury. The patient was connected to mechanical ventilation and was started on inotropic support as well as antibiotic (Tazocin: piperacillin/tazobactam) and fluid resuscitation. 
Gastrografin study through the gastrostomy tube revealed proper tube positioning in the stomach without any leakage around the tube (fig. 2). The patient underwent an abdominal CT scan with oral and intravenous contrast which showed no collection or leakage of the contrast, but identified malpositioning of the tube bumper at the edge of the stomach and not inside of it (fig. 3a, b).

Diagnostic endoscopy to confirm the tube position showed that the bumper was hidden in the posterolateral part of the stomach wall forming a tract inside of it which confirmed the diagnosis of BBS (fig. 4).

The patient was transferred to the operation theater for diagnostic laparoscopy as the tube stoma site showed ischemic marks and pressure necrosis. The laparoscopic procedure was challenged by the presence of a huge amount of intraperitoneal pus and extensive adhesions around the stomach wall which necessitated conversion to open laparotomy (fig. 5a, b). Exploratory laparotomy revealed stomach perforation in the lower posterior wall, operative evacuation of the pus and repair of the stomach wall perforation in two layers was performed followed by insertion of jejunostomy feeding tube (fig. $6 \mathrm{a}-\mathrm{c}$ ). The abdominal wall was left open as damage control.

Postoperatively, inotropic support was stopped and the patient showed signs of clinical recovery with improved kidney function and successful feeding started from the jejunostomy tube. The patient was taken to the operating room for subsequent washout of the peritoneum and abdominal wall closing on the third look, which was successful. The patient was then referred to rehabilitation for long-term care due to severe traumatic brain injury.

\section{Discussion}

PEG was initiated in 1980 to insert a feeding tube into the stomach with the help of endoscopy [10]. It is considered a better choice for the medium- and long-term enteral feeding than the surgical techniques, as it is cost-effective, minimally invasive and usually does not require general anesthesia $[1,11]$. Enteral feeding and stomach decompression are the primary indications for PEG tube insertion. In contrast, patients with hemodynamic instability, abnormal coagulation and distal enteral obstruction are contraindicated for PEG tube insertion [1]. PEG tube placement should be considered based on the necessity, diagnosis and prognosis of the patient. The goal is not only to improve the survival and nutritional status of the patient, but also to improve the quality of life which is not necessarily correlated with nutritional improvement [12]. Although PEG insertion is safe, this technique is also associated with minor (wound infection), or major (BBS, necrotizing fasciitis, and colocutaneous fistula) complications [13].

To the best of our knowledge, this is a unique case report of acute BBS successfully managed by open laparotomy. BBS is an unusual complication with an estimated incidence ranging from 0.3 to $2.4 \%$ [14-16]. It can be manifested with minor complications such as feeding intolerance, peristomal leak, pain, swelling at the site of tube insertion, stoma infection and tube obstruction, whereas major complications including peritonitis, perforation, gastrointestinal bleeding, abdominal wall abscesses or sepsis can rarely happen [8, 9]. In our case, the tube stoma site showed ischemic marks and pressure necrosis 1 week after PEG insertion, and the patient developed signs of sepsis which rapidly progressed to septic shock. McClave and Jafri [17] suggested that the major contributing factor for BBS is the disproportionate compression of tissue between the external and internal bolster of the gastrostomy tube. This mechanism was explained by Schrag et al. [6], who demonstrated how the bumper 


\section{Case Reports in Gastroenterology}

Case Rep Gastroenterol 2016;10:224-232

(c) 2016 The Author(s). Published by S. Karger AG, Basel www.karger.com/crg

Afifi et al:: The Challenging Buried Bumper Syndrome after Percutaneous Endoscopic Gastrostomy

can move from its position inside the stomach to a path between the stomach and the abdominal wall. Therefore, appropriate positioning of the external fixator is crucial to prevent excessive pressure that causes tissue ischemia, necrosis and infection and subsequent development of BBS [8]. The other etiological factors for BBS include inadequate manipulation with excessive traction of the retention system, expansion of the abdominal wall thickness due to weight gain, malnutrition and typical features of the internal bumper [18].

Endoscopy is considered the most definitive test, but ultrasound and CT of the abdomen can also be helpful in the diagnosis [6]. In our case the presentation was 1 week after admission and major complications occurred with peritonitis and development of septic shock. This could be explained by the spastic condition associated with PAID syndrome which is a known manifestation associated with BBS. The case was successfully identified after a suspicious abdominal CT scan finding followed by diagnostic endoscopy. However, the bedside Gastrografin test was misleading.

The time of presentation of BBS varies in the literature; it is commonly expected to occur after 3 weeks to 3 months. Bhat et al. [9] reported a case of early BBS which was managed with tube repositioning endoscopically as no other complications were present, and the authors explained it with severe retching and inadvertent pull during retching. Geer and Jeanmonod et al. [14] observed a case with BBS 3 weeks after PEG tube insertion which was treated with endoscopic replacement.

Acute BBS ( $<4$ weeks after tube insertion) often results from vigorous friction of the cannula secondary to agitation or due to intense tightening of the external bolster [7]. Such cases are not suitable candidates for conservative and endoscopic treatment and so surgical intervention is required [8].

In acute BBS, tube obstruction may not be experienced initially, but as the gastric mucosa gradually covers the internal bolster, the gastrostomy tube eventually turns nonfunctional [14]. Anagnostopoulos et al. [19] reported a case of early BBS with gastrointestinal bleeding. The patient developed abscess, abdominal wall infections and died within $16 \mathrm{~h}$ after the removal of the migrated bumper. In our case, diagnostic laparoscopy revealed a huge amount of intraperitoneal pus and extensive adhesions around the stomach wall, but our case was successfully treated with open laparotomy.

A thorough physical examination should provide clues regarding the non-rotation of the PEG tube within or sliding through the stoma in BBS patients [14]. Therefore, this complication can be easily overcome by appropriate positioning of the PEG tube, leaving a small distance between the skin and the external fixator with daily rotation of the gastrostomy tube by $180-360^{\circ}$ [1]. For appropriate PEG care, proper communication between all caregivers such as relatives, nurses, nursing home staff, home care facilities, nutritional specialist, and digestive endoscopist is extremely important [8].

The primary treatment of BBS is the replacement of the buried tube if the PEG insertion site is salvageable [9]. It has been recommended to remove buried bumper even in asymptomatic patients to prevent major complications like subcutaneous tissue infection, abdominal wall perforation and peritonitis [5]. Various treatment options such as a conservative approach, endoscopic and radiological therapy, surgical incision or simple external traction of the tube can be selected depending upon the type of the PEG tube and depth of disc migration [1]. However, conservative and endoscopic approaches are not indicated for the management of acute BBS. In our case, the laparoscopic procedure was challenging due to the huge amount of intraperitoneal pus and extensive adhesions around the stomach wall and so the patient was managed with open laparotomy. 
In conclusion, acute BBS is a rare complication of PEG tube insertion which could be associated with severe complications such as pressure necrosis, peritonitis and septic shock. Early identification is the mainstay to prevent such complications. Routine examination of the tube positioning and manipulation together with early clinical suspicion is important as well. Urgent endoscopic assessment is warranted in case of doubtful tube malpositioning. Treatment selection is primarily guided by the presenting complications which range from simple endoscopic replacement to surgical laparotomy.

\section{Acknowledgement}

We thank the trauma surgery staff for their cooperation. This case report was approved with a waiver of consent by the Medical Research Center (IRB\#15397/15) Hamad Medical Corporation, Doha, Qatar.

\section{Statement of Ethics}

A waiver of consent was granted as the patient data was retrieved from the medical chart and kept anonymously with full confidentiality with no direct contact with the patient. This case report was approved by the Medical Research Center (IRB\#15397/15) Hamad Medical Corporation, Doha, Qatar.

\section{Disclosure Statement}

The authors have no conflict of interest and no financial issues to disclose.

\section{References}

1 Rahnemai-Azar AA, Rahnemaiazar AA, Naghshizadian R, Kurtz A, Farkas DT: Percutaneous endoscopic gastrostomy: indications, technique, complications and management. World J Gastroenterol 2014;20:7739-7751.

2 Elbaz T, Rejchrt S, Douda T, Cyrany J, Repak R, Bures J: Buried bumper syndrome: an uncommon complication of percutaneous gastrostomy. Report of three cases. Folia Gastroenterol Hepatol 2006;4:61-66.

3 Venu RP, Brown RD, Pastika BJ, Erikson LW Jr: The buried bumper syndrome: a simple management approach in two patients. Gastrointest Endosc 2002;56:582-584.

4 McClave SA, Jafri NS: Spectrum of morbidity related to bolster placement at time of percutaneous endoscopic gastrostomy: buried bumper syndrome to leakage and peritonitis. Gastrointest Endosc Clin N Am 2007;17:731-746.

5 Khalil Q, Kibria R, Akram S: Acute buried bumper syndrome. South Med J 2010;103:1256-1258.

-6 Schrag SP, Sharma R, Jaik NP, Seamon MJ, Lukaszczyk JJ, Martin ND, Hoey BA, Stawicki SP: Complications related to percutaneous endoscopc gastrostomy (PEG) tubes. A comprehensive clinical review. J Gastrointestin Liver Dis 2007;16:407-418.

-7 Rino Y, Tokunaga M, Morinaga S, Onodera S, Tomiyama I, Imada T, Takanashi Y: The buried bumper syndrome: an early complication of percutaneous endoscopic gastrostomy. Hepatogastroenterology 2002;49:1183-1184.

8 Cyrany J, Rejchrt S, Kopacova M, Bures J: Buried bumper syndrome: A complication of percutaneous endoscopic gastrostomy. World J Gastroenterol 2016;22:618-627.

-9 Bhat G, Suvarna D, Pai CG: Acute buried bumper syndrome: an endoscopic peg tube salvage approach. Indian J Med Sci 2010;64:234-236. 


\section{Case Reports in \\ Gastroenterology}

\begin{tabular}{l|l}
\hline Case Rep Gastroenterol 2016;10:224-232 \\
\hline $10.1159 / 000446018$ & $\begin{array}{l}\text { C) 2016 The Author(s). Published by S. Karger AG, Basel } \\
\text { www.karger.com/crg }\end{array}$
\end{tabular}
www.karger.com/crg

Afifi et al: The Challenging Buried Bumper Syndrome after Percutaneous Endoscopic Gastrostomy

10 Gauderer MW, Ponsky JL, Izant RJ: Gastrostomy without laparotomy: a percutaneous endoscopic technique. J Pediatr Surg 1980;15:872-875.

-11 Ho CS, Yee AC, McPherson R: Complications of surgical and percutaneous nonendoscopic gastrostomy: review of 233 patients. Gastroenterology 1988;95:1206-1210.

12 Bannerman E, Pendlebury J, Phillips F, Ghosh S: A crosssectional and longitudinal study of healthrelated quality of life after percutaneous gastrostomy. Eur J Gastroenterol Hepatol 2000;12:1101-1109.

$>13$ Biswas S, Dontukurthy S, Rosenzweig MG, Kothuru R, Abrol S: Buried bumper syndrome revisited: a rare but potentially fatal complication of PEG tube placement. Case Rep Crit Care 2014;2014:634953.

-14 Geer W, Jeanmonod R: Early presentation of buried bumper syndrome. West J Emerg Med 2013;14:421-423.

15 Pop GH: Buried bumper syndrome: can we prevent it? Pract Gastroenterol 2010;84:8-13.

16 Lee TH, Lin JT: Clinical manifestations and management of buried bumper syndrome in patients with percutaneous endoscopic gastrostomy. Gastrointest Endosc 2008;68:580-584.

17 McClave SA, Jafri NS: Spectrum of morbidity related to bolster placement at time of percutaneous endoscopic gastrostomy: buried bumper syndrome to leakage and peritonitis. Gastrointest Endosc Clin N Am 2007;17:731-746.

18 Boyd JW, DeLegge MH, Shamburek RD, Kirby DF: The buried bumper syndrome: a new technique for safe, endoscopic PEG removal. Gastrointest Endosc 1995;41:508-511.

19 Anagnostopoulos GK, Kostopoulos P, Arvanitidis DM: Buried bumper syndrome with a fatal outcome, presenting early as gastrointestinal bleeding after percutaneous endoscopic gastrostomy placement. J Postgrad Med 2003;49:325-327.

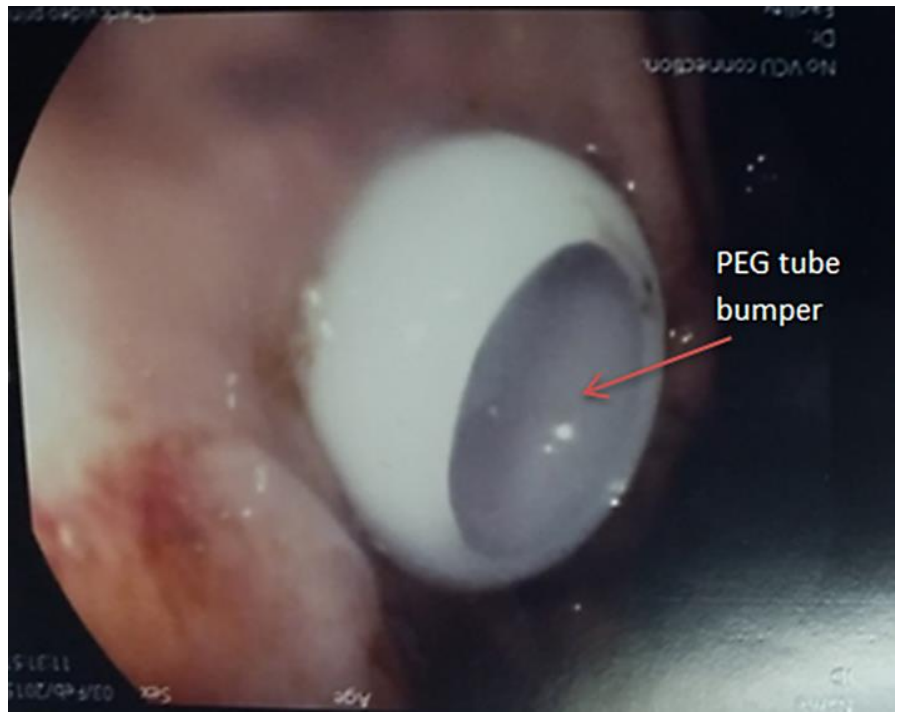

Fig. 1. Endoscopic confirmation of the bumper position (the arrow shows the PEG tube bumper). 


\section{Case Reports in Gastroenterology}

\begin{tabular}{l|l}
\hline Case Rep Gastroenterol 2016;10:224-232 \\
\hline $10.1159 / 000446018$ & $\begin{array}{l}\text { ○ 2016 The Author(s). Published by S. Karger AG, Basel } \\
\text { www.karger.com/crg }\end{array}$ \\
\hline
\end{tabular}

Afifi et al:: The Challenging Buried Bumper Syndrome after Percutaneous Endoscopic Gastrostomy

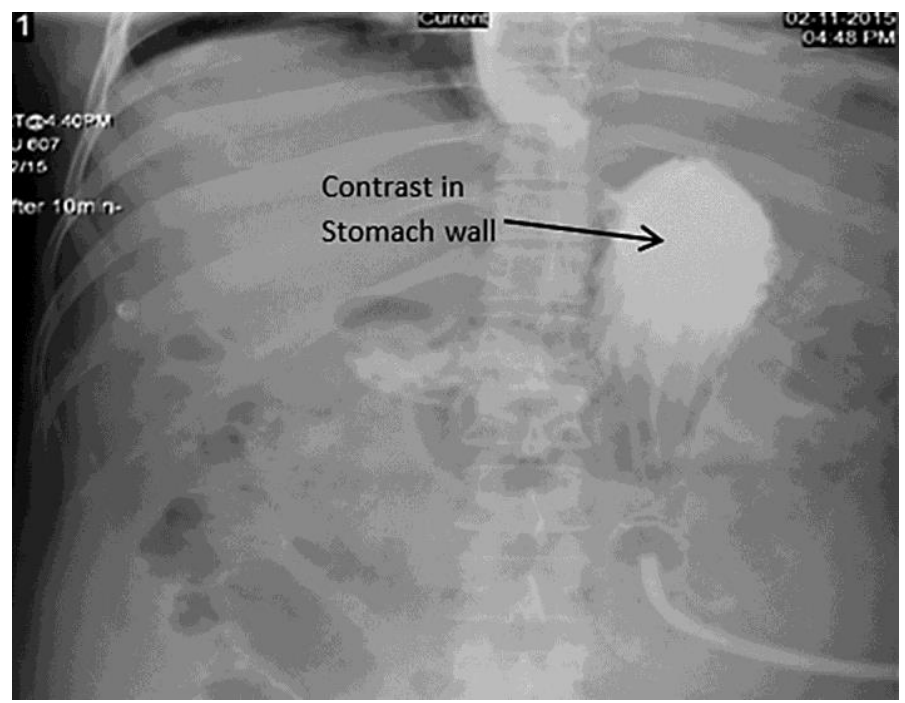

Fig. 2. Gastrografin study showed proper position of the gastrostomy tube in the stomach with no leak around (the arrow shows the contrast in the stomach wall).
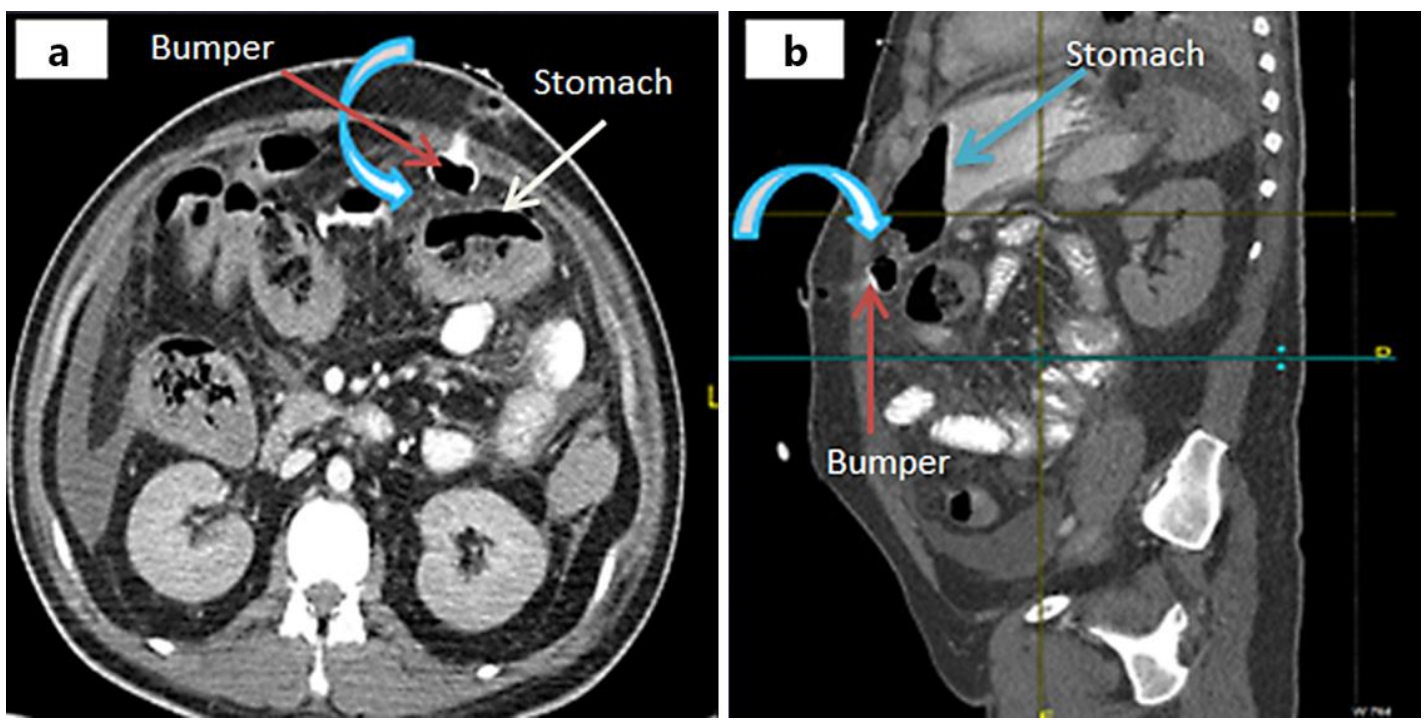

Fig. 3. a CT scan abdomen with oral and i.v. contrast showed no collection or leakage but suspicion of bumper position at the stomach edge with intraperitoneal fluid collection (the white arrow indicates the stomach and the red arrow shows the bumper). b CT scan of the abdomen with oral and i.v. contrast showed no leakage but suspicion of bumper position at the stomach edge with intraperitoneal fluid collection (the white arrow indicates the stomach and the red arrow shows the bumper). 

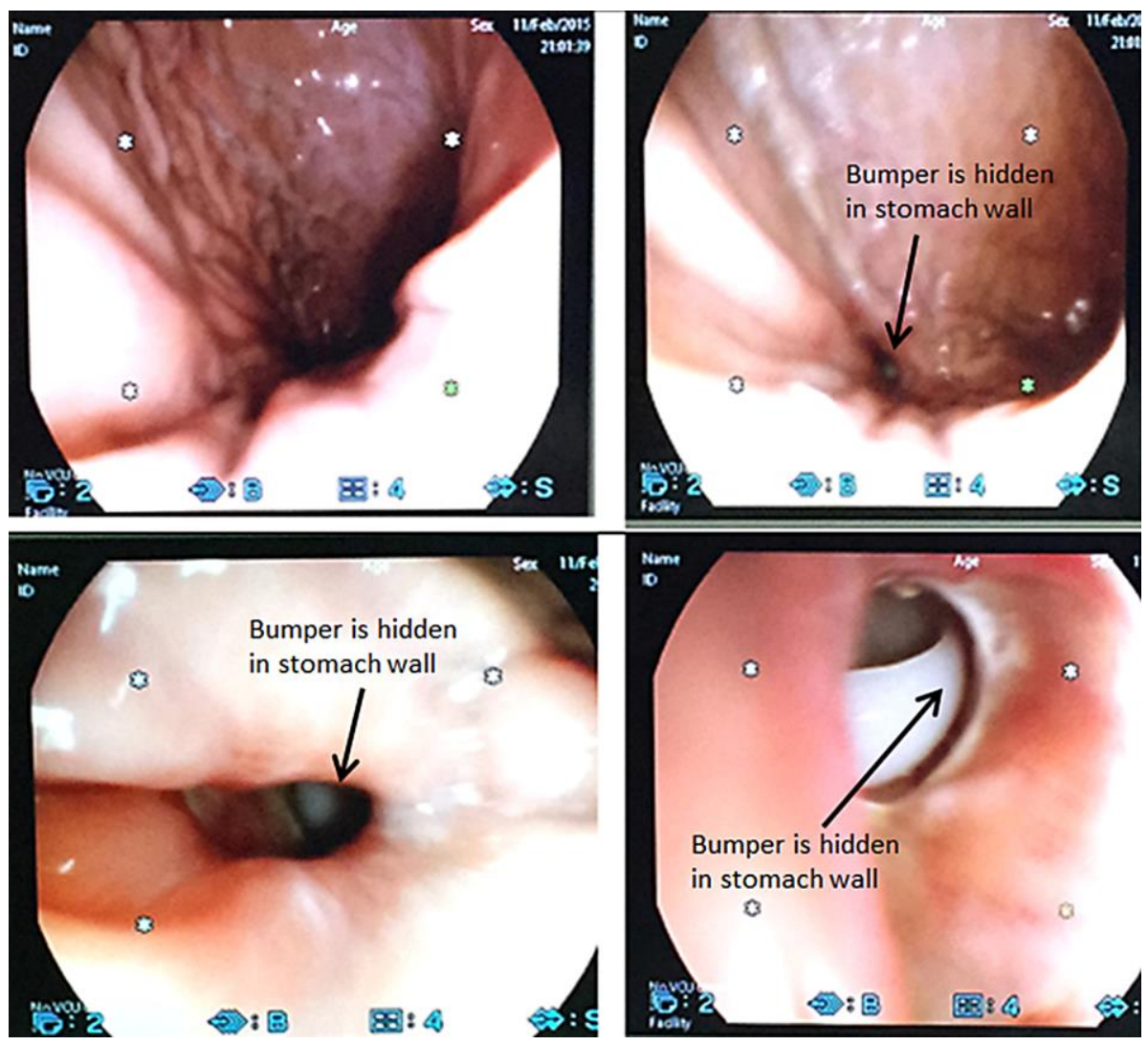

Fig. 4. Endoscopic diagnosis of BBS (arrows show that the bumper is hidden in the stomach wall).
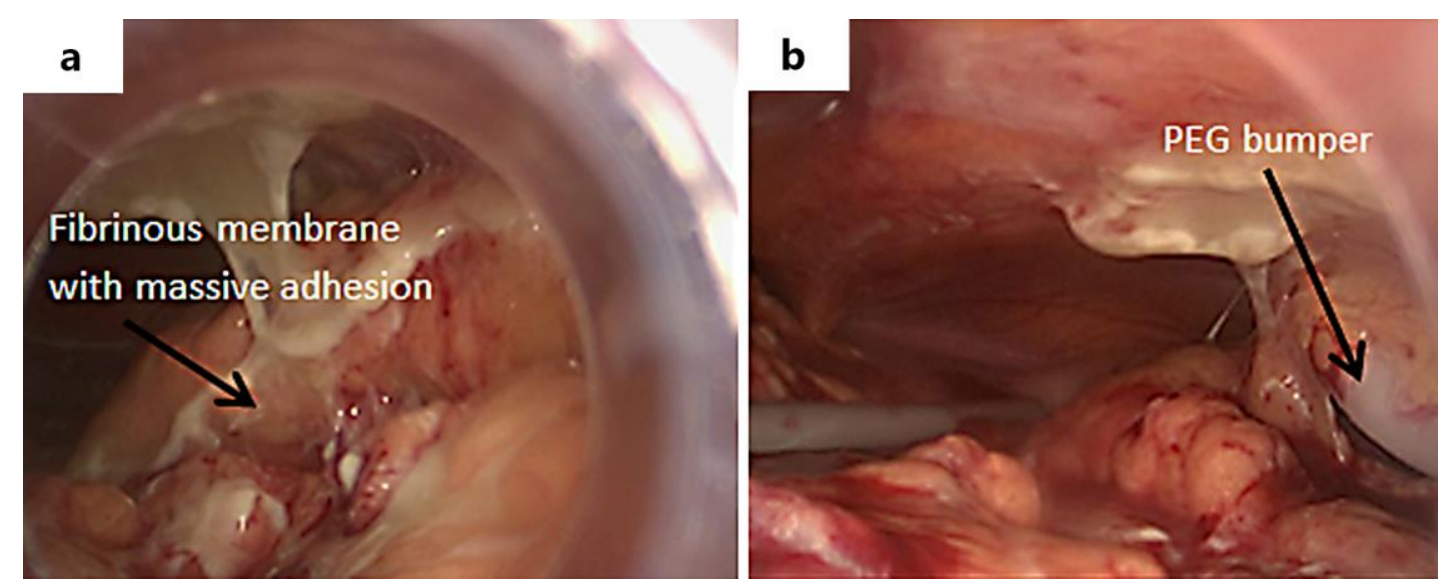

Fig. 5. a Laparoscopic exploration showed free pus and massive adhesions (the arrow indicates the fibrinous membrane with massive adhesion). b Laparoscopic exploration showed the tube bumper at the inner abdominal wall which slipped after dissection (the arrow indicates the PEG bumper). 

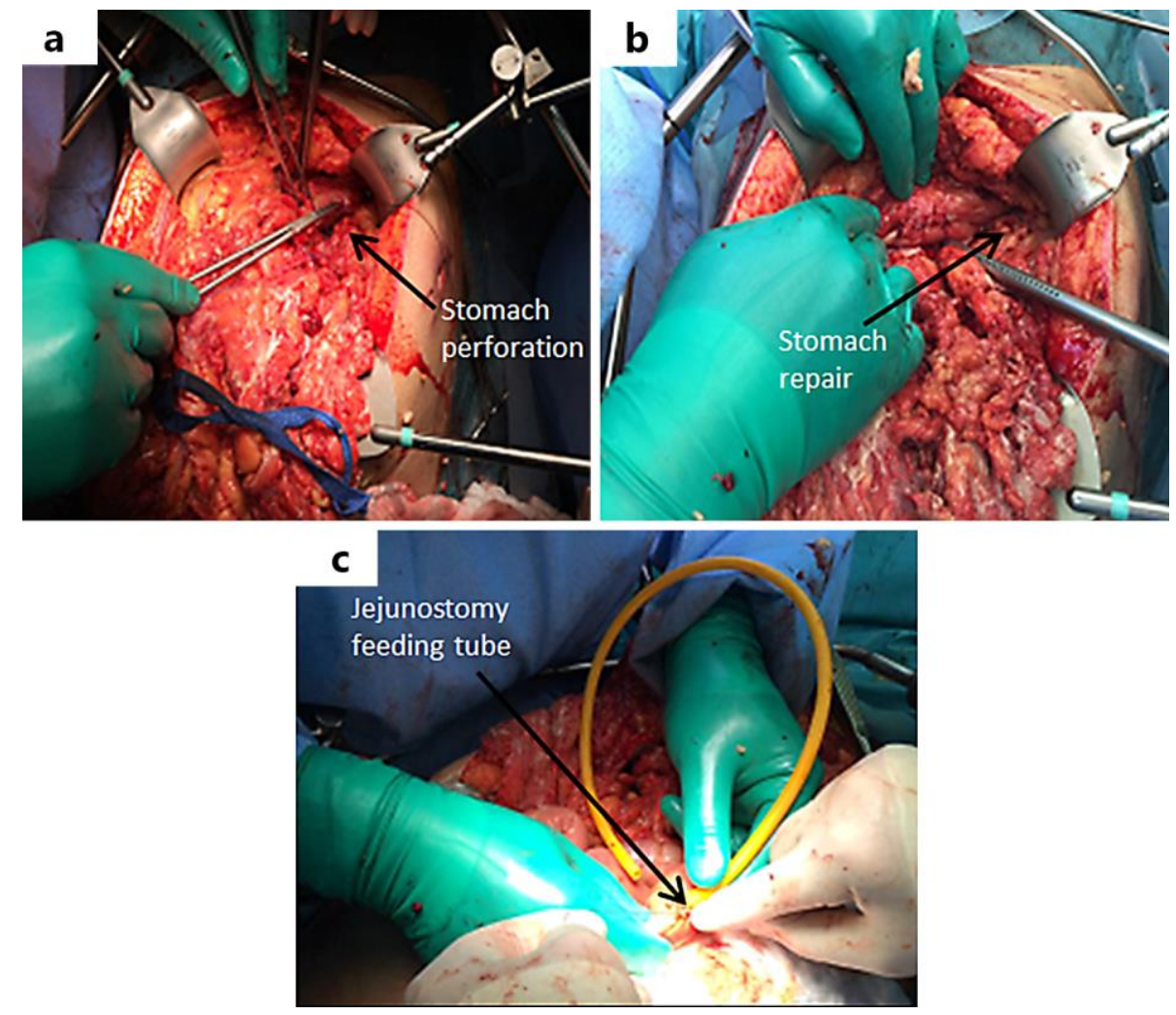

Fig. 6. a Laparotomy: stomach perforation (black arrow). b Laparotomy: repair of the stomach wall (black arrow). c Laparotomy: jejunostomy feeding tube (black arrow). 